\title{
ODESSE: A NEW TOOL FOR SIMULATION AND DESIGN OF SOLAR DESICCANT COOLING SYSTEMS IN ENERGY EFFICIENT BUILDINGS
}

\author{
Beccali M. ${ }^{1 *}$, Bertini I. ${ }^{2}$, Di Pietra B. ${ }^{1}$, Finocchiaro P. ${ }^{1}$, Ceravolo.F ${ }^{2}$, Puglisi.G ${ }^{2}$ \\ ${ }^{1}$ DREAM - Dipartimento di Ricerche Energetiche e Ambientali \\ Università degli Studi di Palermo. Viale delle Scienze, Edificio 9. 90128 Palermo. Italy \\ phone: +39091236211 ; fax: +39091484425 \\ ${ }^{2}$ ENEA UTEE-GED - Via Anguillarese, 301 - 00123 Roma (Italy) \\ *Corresponding Author, marco.beccali@dream.unipa.it
}

\begin{abstract}
A set of mathematical model of Solar Desiccant and Evaporative Cooling systems and components has been developed and integrated in a novel software platform for dynamic simulation of the whole building-HVAC system called ODESSE (Optimal DEsign Smart Energy System).

The core of the work was to link the new sub-routines developed for the simulation of DEC systems to the others already available in the ODESSE platform and to develop the user interface. ODESSE platform has been developed by ENEA (Italian National Agency for New Technologies, Energy and Environment), using MATLAB/Simulink software. The models of DEC systems have been implemented in co-operation with the department DREAM of the University of Palermo. The software will be available soon as freeware on the ENEA website.

This tool will allow the user to design and test several configurations of desiccant AHUs, to simulate them and to compare with a reference conventional system making possible a performance analysis based on hourly simulations. Architecture of the code, description of the user interface and the main outputs displayed by the tool are presented.
\end{abstract}

\section{Introduction}

The aim of this study is the development and implementation of a mathematical model of Solar Desiccant and Evaporative Cooling systems (DEC) in a novel software platform for dynamic simulation of the whole building-HVAC system called ODESSE.

This paper describes the work to develop of a specific user interface into ODESSE platform to design and simulate different DEC configurations and to compare it with a reference conventional system. ODESSE allows to assess the technical-economic feasibility of interventions for the energy improvement of existing buildings or districts, and it is supposed to be decisive in the ecobuilding's design. 


\section{Dynamic simulation software: O.DES.S.E.}

O.DES.S.E. is a freeware software platform for dynamic simulation of the whole building-HVAC system which allow the assessment of the energy consumption by means of a thermo-physical description of the building envelope, of the connected systems under given climatic conditions (temperature, solar radiation, humidity).

Temperature and radiation input to the model are produced by a climatic data generator, called Neural Weather Generator (NWG) developed by ENEA. Unlike common models, in which data are given by a database of historical values of several locations, the NWG estimates climatic values through neural evolutive networks. This networks are trained with weather data (mean monthly values) of Italian provinces (UNI 10349) and verified by ENEA's solar radiation atlas.

In particular, O.DES.S.E. is able to dynamically simulate the performance of building-HVAC system in real condition of work, with actual energy costs, taxis and billing rules and therefore allow to estimate either technical and economic feasibility of the whole system. O.DES.S.E. also represents an excellent tool for planning energy policy actions by performing analytical studies (calculation of energy demand, characterizations of the structures, plant layout, etc..) as well as with sensitivity analyses of energy savings and payback time of investment as result of new regulations or incentives.

Mathematical models are made with a set of differential equations in time domain, with variables parameters. It is based on knowledge of the physics of heat exchanges, generated distribution system, (including renewables), networks and dynamics phenomena of all variables that influence the thermal behavior of buildings.

Assessment of cooling load is done using the RTS method. This is a simplified cooling load calculation method, documented in the ASHRAE handbook-fundamentals 2001.

This method accounts for time delay and attenuation of heat flux between internal and external surfaces due to the fact that while convective part of heat gain become immediately cooling load, radiative part is first absorbed by wall and then, after a time delay, transferred by convection to room air. So the time series coefficients are introduced (radiant and conduction time factors), that distributes the heat gain over time. Radiant time factors reflect the percentage of radiant heat gain that becomes cooling load, while conduction time factors reflect the percentage of heat gain of a wall or roof that becomes heat gain. By definition, the sum of radiant and conduction time series must total equal to $100 \%$.

The platform is composed of an interface, developed in JAVA and of a kernel developed in MatlabSimulink.

\section{Description of the DEC model}

The models of DEC systems have been implemented on the Matlab/Simulink platform through the development of new blocks and also by adapting blocks of the SIMBAD toolbox libraries (air fans, rotating heat exchanger, simple static models of heating and cooling coils, divergent and convergent valves).

In order to simulate different DEC configurations, a new architecture of the code and the user interface have been implemented to link new sub-routines with the plants and building models of the main ODESSE code. 
The model is composed of several interconnected blocks, which simulate the components of Fig. 1.

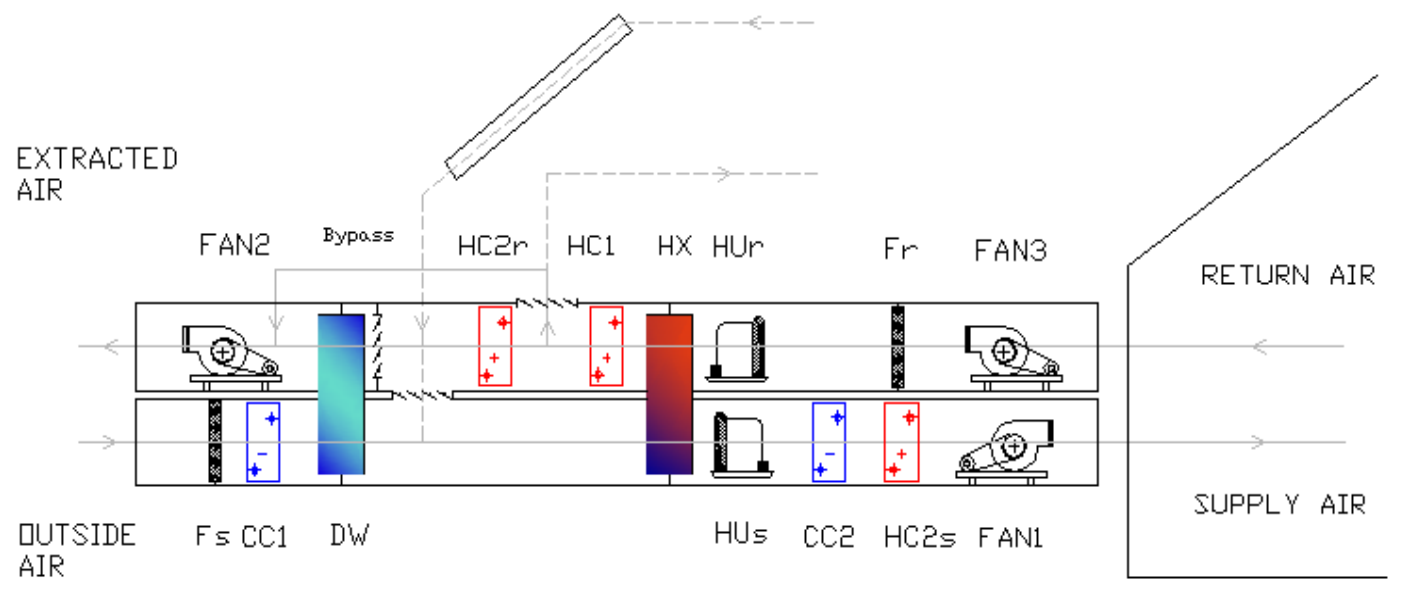

Fig. 1. General scheme and components of the DEC model implemented

The main input and output of each block are vectors which contain the parameters of the air before and after that component: temperature $\left[{ }^{\circ} \mathrm{C}\right]$, absolute humidity $\left[\mathrm{kg}_{\mathrm{v}} / \mathrm{kg}_{\mathrm{a}}\right]$, pressure $[\mathrm{Pa}]$ and flow rate $[\mathrm{kg} / \mathrm{h}]$.

Outside air conditions in terms of temperature, absolute humidity and pressure are determined with one hour time step, during annual simulation, by the NWG of ODESSE platform.

New blocks have been implemented in Simulink for humidifiers (HU) and desiccant wheels (DW), as well as for the control strategy.

Desiccant wheel has been implemented on the basis of the model developed by Beccali et al. [4]-[5], which has been derived by interpolating experimental data obtained from manufacturers and by developing correlations for predicting outlet temperature and absolute humidity. Specifically, the model is used to predict the performance of three types of desiccant rotors manufactured by using different kind of solid desiccants: Silica Gel and LiCl.

The component and AHU models have been tested and validated with experimental data sets [3].

The user interface allows to describe various configurations of DEC systems. A .m file of Simulink is then launched automatically when the simulation is started.

Every DEC configuration is controlled according to a specific control strategy typical for DEC systems, implemented in a block of Simulink with different modes of operation. [3]. The Mode selector block, which is activated every 15 minutes, checks the supply air conditions. If temperature and relative humidity are within the desired ranges, the operation mode will not change; on the contrary, if any variable is out of the range, the operation mode will be increased or reduced, to increase respectively the AHU heating or cooling power. The dead bands around the set points are \pm $0.5^{\circ} \mathrm{C}$ for temperature and $\pm 5 \%$ for relative humidity.

In the cooling season, three operation modes are possible. The system starts in the ventilation mode, where no active air handling is performed, but only the fans are switched on (mode 0 ). In mode 1, only indirect evaporative cooling is performed by means of a heat recovery wheel and the humidifier on the 
return side. In mode 2 , the solar desiccant cooling cycle is operated by means of the regeneration coil (HC2r), solar collectors, desiccant wheel and supply and return humidifiers. In mode 3 , the auxiliary back-up system, as well as the cooling coils $\mathrm{CC} 1$ and $\mathrm{CC} 2$, are switched on to meet the cooling loads in case of high loads.

In the heating season, the first operation mode (-1) allows heat recovery and solar heating, while in mode -2 , the auxiliary back-up system is activated.

\section{Solar DEC user interface}

The ODESSE user interface is implemented in Java ambient according to criteria of intuitiveness to permit its use even to an inexperienced user of dynamic simulation. The user can insert information regarding physical, structural and geometrical building data, location and climatic zone, internal gains profile, heating and cooling system (Fig.2 ).
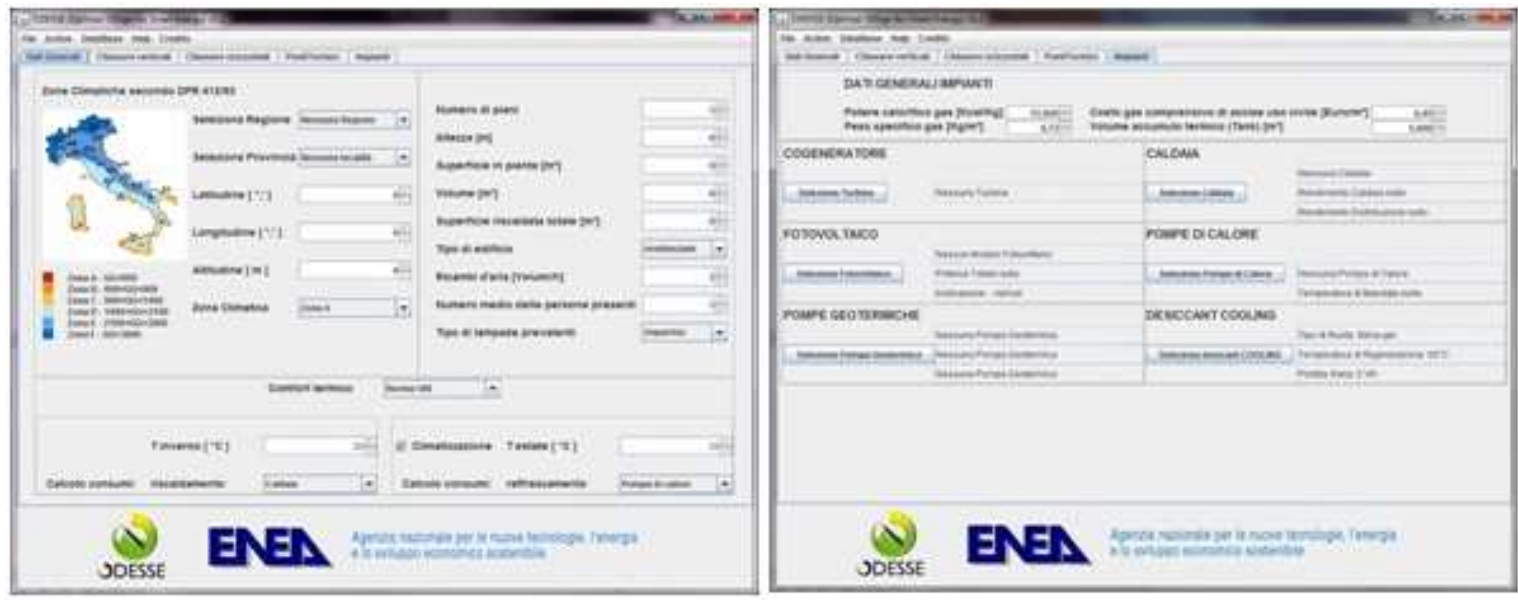

Fig. 2. ODESSE user interface : Climatic Zone and general Building data

In particular, Solar DEC user interface allows to chose one of the following five AHU configurations:

- A - standard DEC

- B - standard DEC with solar collectors;

- C - standard DEC with solar collectors and auxiliary cooling;

- D - standard DEC with two auxiliary cooling coils and condensation heat recovery;

- conventional AHU system.

In order to choose which component is present in each of the various configurations, several vectors are defined in the initialization file to drive additional input of mathematical models according to the following table (Tab.1).

The user can set the air flow rate, the presence of the heating coil for winter operation and efficiency of the rotary heat exchanger (low, medium or high). In Fig. 3 a screen shot of the main interface of the tool is reported. 
Table 1. Components of each DEC configuration

\begin{tabular}{|c|c|c|c|c|c|}
\hline \multirow[b]{2}{*}{ Component } & \multirow[b]{2}{*}{ Symbol } & \multicolumn{4}{|c|}{ DEC Configuration } \\
\hline & & $\mathrm{A}$ & $\mathrm{B}$ & $\mathrm{C}$ & $\mathrm{D}$ \\
\hline Filter (supply air) & Fs & - & - & - & - \\
\hline $\begin{array}{l}\text { Cold battery / pre- } \\
\text { dehumidification }\end{array}$ & $\mathrm{CC} 1$ & & ש & $\mathbf{\square}$ & \\
\hline Desiccant wheel & DW & $\mathbf{\square}$ & $\mathbf{\square}$ & 口 & \\
\hline Heat exchanger & HX & $\square$ & $\square$ & $\square$ & $\mathbf{\square}$ \\
\hline Humidifier (supply air) & Hus & $\mathbf{\square}$ & $\mathbf{\square}$ & $\square$ & $\mathbf{\square}$ \\
\hline Sensible aux cooling coil & $\mathrm{CC} 2$ & & $\mathbf{\square}$ & $\mathbf{\square}$ & $\mathbf{\square}$ \\
\hline Heating coil & $\mathrm{HC} 2 \mathrm{~s}$ & $\mathbf{a}^{1}$ & $\mathbf{a}^{1}$ & $\mathbf{a}^{1}$ & $\mathbf{\square}$ \\
\hline Fan (supply air) & Fan 1 & $\boldsymbol{\square}$ & घ & घ & $\boldsymbol{\square}$ \\
\hline Filter (return air) & $\mathrm{Fr}$ & 口 & $\square$ & $\square$ & $\mathbf{\square}$ \\
\hline Fan (return air) & Fan 3 & $\mathbf{u}^{2}$ & $\mathbf{n}^{2}$ & $\mathbf{a}^{2}$ & $\mathbf{v}^{2}$ \\
\hline Humidifier (return air) & Hur & $\square$ & $\square$ & $\square$ & \\
\hline Condensation heat recovery coil & $\mathrm{HC} 1$ & & & - & \\
\hline Solar regeneration coil & $\mathrm{HC} 2 \mathrm{r}$ & $\mathbf{v}^{3}$ & $\mathbf{a}^{3}$ & $\boldsymbol{\square}^{3}$ & \\
\hline Fan (return air) & Fan 2 & $\mathbf{\square}$ & ש & घ & घ \\
\hline Notes: & \multicolumn{5}{|c|}{$\begin{array}{l}{ }^{2} \text { only present when air collectors are used } \\
{ }^{3} \text { if air collectors are used, the solar regeneration coil HC2r is absent; instead, the air } \\
\text { flows through the collector }\end{array}$} \\
\hline
\end{tabular}

Air treatment in the desiccant cooling process is achieved by means of three successive phases: an initial process of dehumidification by adsorption in the desiccant wheel, a subsequent indirect evaporative cooling achieved with the flow of return air from the building and finally, when required, direct evaporative cooling to bring the supply air to desired inlet conditions.

The user can set collector type and surface. Only in case of water collectors a bypass parameter allows the user to modify the flow rate of the regeneration air which regenerates the desiccant wheel.

In order to simply identify the configuration of the AHU, the scheme of the chosen system with every component involved is visualized. Furthermore the user can easily add or remove components such as additional cooling or heating coil, change the collector type and visualize every set point used for the control of the cooling or heating coils. 


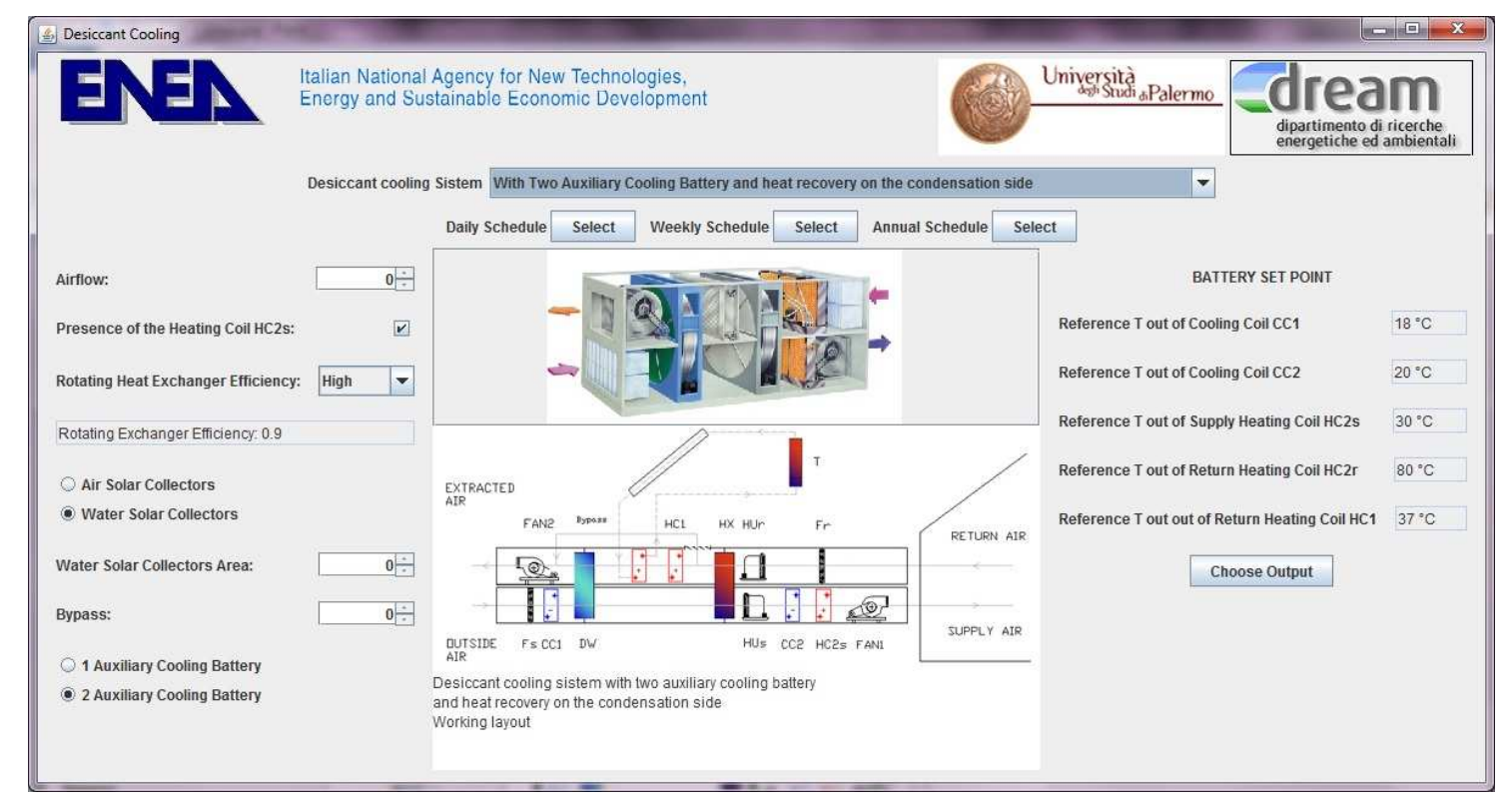

Fig. 3. ODESSE user interface : Standard DEC with solar collector auxiliary cooling coils and condensation heat recovery configuration plants

The user can set different schedules of operating hours for weekdays and weekends (Fig.4) and time periods for operation in heating, cooling or ventilation mode.

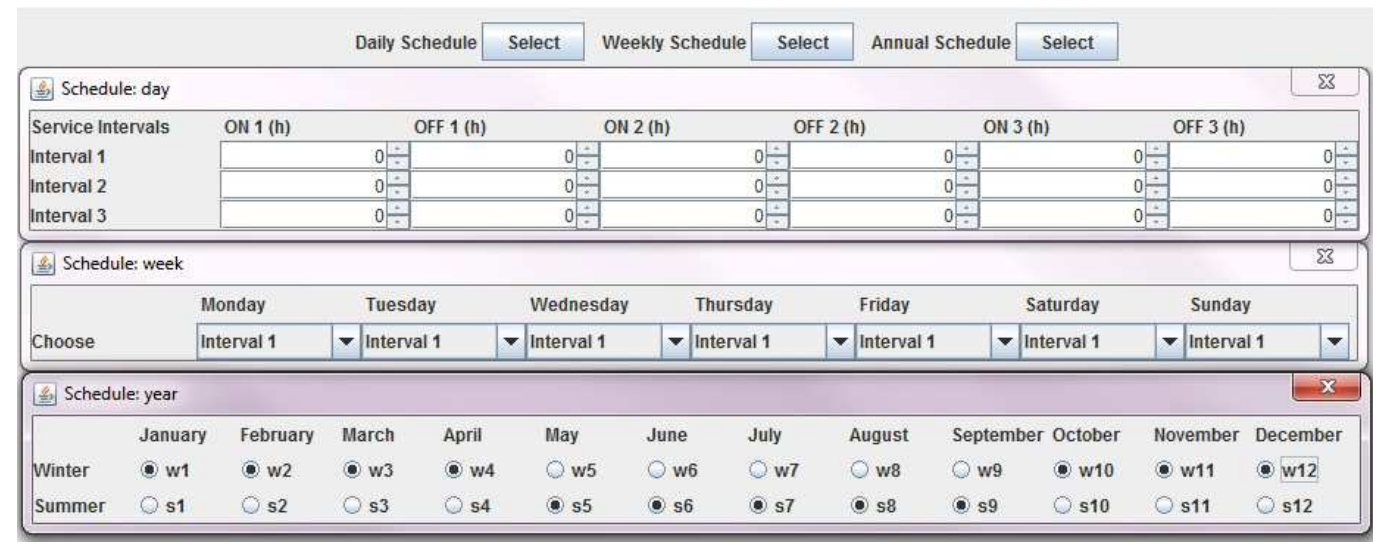

Fig. 4. Schedule working hours

\section{Description of the outputs}

The tool permits the performance evaluation and comparison of different desiccant AHU, allowing a detailed analysis of the system through the visualization of many outputs at hourly, monthly and seasonal base. Users can easily change the time period for which outputs should be shown.

In order to help the user to select the appropriate heating and cooling coils, a pre-design function was integrated which returns minimum and maximum peak values of required power registered during the 
simulation. Furthermore, a synthetic technical report containing the most important energy performance indicators of the system can be printed or exported into a separate file (Fig.6). The output report contains the main features of the system and seasonal energy performances separately for winter and summer operation such as cooling/heating energy delivered, auxiliary energy required, solar fraction, thermal and electrical COP and others.

\begin{tabular}{|l|l|}
\hline Gas Consumption & $v$ \\
\hline Electric Consumption & $\nabla$ \\
Thermal COP & $\nabla$ \\
Electric COP & $\square$ \\
Winter Solar Fraction & $\nabla$ \\
Summer Solar Fraction & $\square$ \\
Peak Power CC1 & $\square$ \\
Peak Power CC2 & $\square$ \\
Peak Power HC1 & $\square$ \\
Peak Power HC2r & $\square$ \\
\hline \hline
\end{tabular}

Fig. 5. Example of window where the selection of desired outputs can be done

\section{ENEA

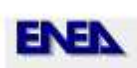

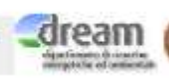
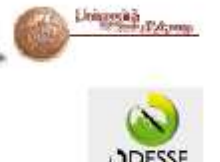

ENEA

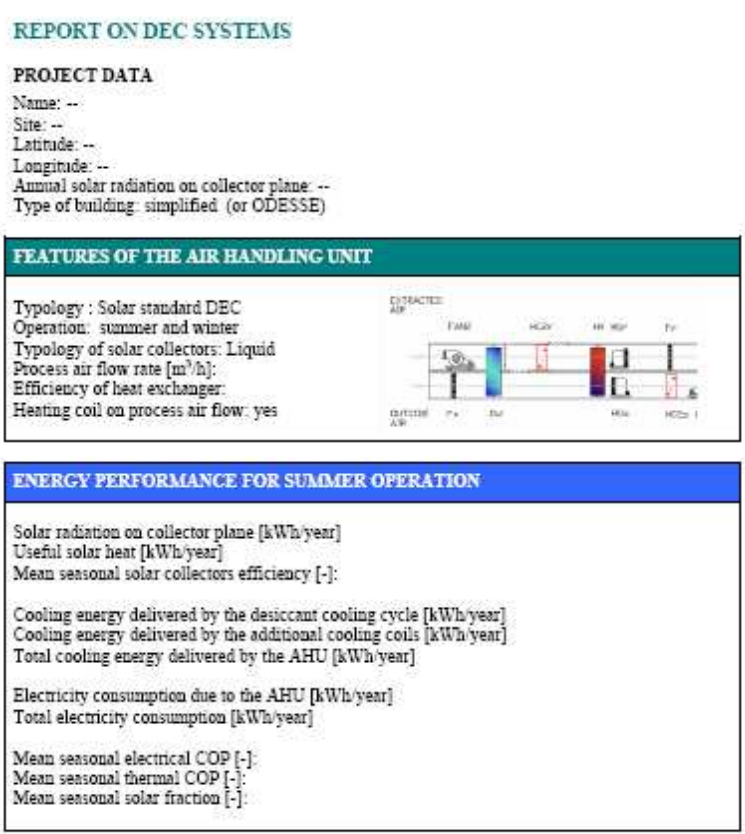

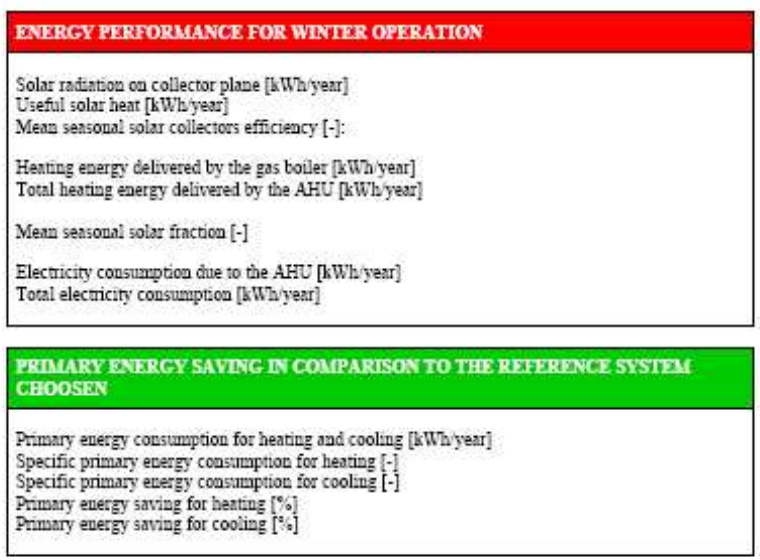

Fig. 6. Output report on DEC system containing main features and energy performance indicators 


\section{Conclusions}

The design of a Solar DEC system is a difficult task. Wrong sizing of equipment and auxiliaries often leads to unfair performance figures causing in some cases also negative energy saving. For this reason the use of a detailed dynamic simulation tools is recommended. ODESSE-DEC software represent an useful tool for this task which can avoid the use of time consuming scientific softwares. His user friendly interface has been designed to give the possibility to simulate with easy and fast input four different configurations of desiccant AHUs coupled with solar water or air collectors. The model contains default performance indexes of each components but giving to the user the possibility to change these figures with other one related to market available equipment.

The HVAC system is connected to a dynamic model of the building for a reliable calculation of heating and cooling load. The user can also perform a comparison with a conventional AHU in order to assess the achievable energy saving.

Main performance index are provided in a detailed output report as well as hourly and monthly diagrams for a set of selectable variables dealing with building demand and HVAC performances.

Further development of the software has the aim to increase the number of AHU configurations (by giving the possibility to the user to design a full customised unit), to enhance the information provide in the report (including monthly and hourly diagrams for peak load days) and to enlarge the weather data base (today available only for Italian locations).

\section{References}

[1]I. Bertini, F. Ceravolo, M. De Felice, B. Di Pietra, F. Margiotta,, S. Pizzuti, G. Puglisi: Sviluppo dell'ambiente di progettazione Optimal DESign for Smart Energy : ODESSE - Ricerca di Sistema, Aprile 2009

[2] M.Beccali, P. Finocchiaro, R.Padalino, B.Di Pietra, A. Messineo: Definizione di sistemi DEC di riferimento e raccolta algoritmi disponibili per componenti unitari” - Ricerca di Sistema, Aprile 2009

[3] Beccali M, Bertini I., Di Pietra B, Finocchiaro P, Luna M: Desiccant cooling simulation and design in Matlab/Simulink environment: implementation and validation of the model - Terza Conferenza internazionale: Solar Air-Conditioning 30 Settembre 2009, Palermo, Italia.

[4] Beccali M., Butera, F., Guanella, R. and Adhikari, R.S. "Simplified models for the performance evaluation of desiccant wheel dehumidification”. Int. Journal of Energy Research, Wiley, vol. 27/2003, pp. 17-29.

[5] Beccali M., Butera, F., Franzitta V., and Adhikari, R.S. "Update on desiccant wheel model". Int. Journal of Energy Research, Wiley, vol. 28/2004, pp. 1043-1049.

[6] Ceravolo F. , Di Pietra B. , Pizzuti S. , Puglisi G : Neural models for ambient temperature modeling, CIMSA 2008. 2008 IEEE International Conference on. Computational Intelligence. for Measurement Systems. and Applications. Istanbul, Turkey, 14-16 July 2008

\section{Acknowledgments}

This work has been carried out in the framework of the Research "Promotion of efficient technologies" of the Plan Agreement between the Italian Ministry of economic Development (MSE) and ENEA. 